\title{
The Implications of Thermogenic Modification for Anthropological Recovery of Burned Bone
}

\author{
Meaghan Efford* \\ The University of Victoria \\ meaghan.efford@gmail.com
}

\begin{abstract}
Burn trauma is prevalent in both archaeological and forensic records. It causes thermogenic modifications that have implications for the discipline of anthropology. Anthropologists and medical professionals are frequently the experts called to address burn trauma cases, often in the role of forensic anthropologists. This project seeks to discuss the processes of burn trauma and the resulting changes, as well as how the professionals in the fields of archaeology, anthropology, and medicine are discussing the recovery and analysis of burned human remains. An experiment is used to demonstrate these changes and compare them to those documented by experts in the field. A literature review discusses the processes of burn trauma and the resulting thermogenic modifications that are seen in the scholarly literature on the topic. The author makes recommendations for future research, namely the inclusion of weight in the recorded factors during experimentation and continued research into the recovery of burned remains. The author argues that the bioarchaeological approach of forensic anthropology benefits from the combined experience of archaeologists, biological anthropologists, and medical experts who have a background in osteology and biomechanics.
\end{abstract}

Keywords: Archaeology; forensic anthropology; biological anthropology; burn trauma; bone; forensic medicine; bioarchaeology; osteology; biomechanics

\section{INTRODUCTION}

$\mathrm{F}$ orensic anthropology is a relatively new discipline, and as such it is undergoing the creation of standards and methods. One aspect that still requires attention is that of the specific processes that occur during burn trauma, and the changes that are the result of those processes. Remains undergo a series of biochemical processes when exposed to thermal trauma. These processes produce significant and predictable effects, or thermogenic modifications, that influence the objects of the trauma: In the cases of forensic anthropology, these objects are usually human remains. Factors causing death may be trauma caused by fire, smoke inhalation, or other causes, and the remains that are recovered can be burned on a wide spectrum from mildly scorched to ash. Burn trauma can occur in a number of ways, both forensic and archaeological,

\footnotetext{
${ }^{*}$ I would like to thank my supervisor Dr. Daromir Rudnyckyj for his guidance and advice throughout this project. I would also like to thank my second supervisor, Dr. Ranald Donaldson, for his expertise, advice, and guidance in the shaping and execution of this project. Dr. Donaldson attended the first run of the experiment included in this project in November 2015 and assisted in data documentation. Without them this project would not have been possible. I would also like to thank Becky Wigen, the Senior Lab Instructor and Co-Undergraduate Advisor at the University of Victoria. Becky allowed me to perform my burn experiment on her property at both events and gave me valuable advice in the shaping of the burn experiment. Thank you to my Honours cohort, I appreciate all of your support. Finally, I would like to thank my assistant for the second burn in April 2016, my sister Siobhan Efford. Siobhan documented the data that I gathered and supported me throughout this project.
} 
from cremation to vehicular crashes, or explosions and factory fires. War crimes and mass disasters can also result in burn trauma. Forensic cases are those that fall under legal jurisdiction, usually because the cause and manner of death or the source of the remains are suspicious.

Burn trauma is a sub-topic of thermal trauma, which is trauma caused by exposure to extreme temperatures. We see this in many contexts, not all of them legally relevant. Cremations are seen in the archaeological record, in both historical and contemporary contexts. Cremations can be buried with or without a container, which will also influence preservation. We see fire used as both a weapon and as a tool to hide evidence of trauma or identity. Thermogenic modifications are changes caused by exposure to extreme temperatures, and burn trauma causes modifications that result in changes in size, shape, weight, integrity, and texture of remains. Further, the molecular structure of bone changes when exposed to the burning process, and soft tissue can burn away completely. This can influence the recovery of the remains and any associated data. This project seeks to address these specific processes and their resulting modifications, and their significance to biological anthropology and archaeology. These two subfields are often employed, usually through the role of the forensic anthropologists, in addressing cases of burn trauma in contemporary contexts. This research project poses the question: What thermogenic modifications are caused by burn trauma, and how do experts in the fields of biological anthropology and archaeology approach these cases? Relevant to the discussion of this question is the following guiding question: What is the sequence of burn trauma events over time, and what are the effects of these modification events that we see in the medical, archaeological, and anthropological records?

This project seeks to combine the research on the processes of burn trauma with the research on recovering burned human remains. To do this, I build on the subfield of bioarchaeology, drawing on theoretical perspectives from within the social science and medical fields and explain these perspectives and how they work together in forensic anthropology. Then, I describe my approach to my own experiment process, and the limitations of this research. I present leading research in the field of burn trauma and highlight key arguments that pertain to recovering and analysing burned human remains in forensic and archaeological contexts. My contribution to this field of research is the experiment: I demonstrate the various processes of burn trauma through a series of photographs. I then compare the modifications present in the experiment with those described in the literature. Following, I discuss the individual factors of burn trauma and how they interact, and their significance to forensic anthropology and bioarchaeology. In the discussion section I take this data and my analysis and make two arguments. First, I argue that a better understanding of the biochemical processes of burn trauma will enable forensic anthropologists to more effectively recover and document burned remains. Second, I argue that these processes result in significant structural changes that have substantial impact on the size, weight, morphology, and structural integrity of the remains that can make recovery, transport, and analysis of the remains difficult. I also argue that burn trauma research is imperative to the field of forensic anthropology due to the complex nature of this type of trauma. Trauma caused by extreme heat is prevalent: many events, whether accidental, environmental, or forensic, can all result in burn trauma. Whether archaeological or forensic, remains subjected to burn trauma require a different approach than those subjected to any other type of trauma. A multidisciplinary approach is necessary to the study and recovery of thermal trauma: the biochemical nature of this trauma is countered by cultural and funerary influences, and this requires a holistic approach to fully understand what is involved. In the conclusion, I summarize my argument and make some suggestions for the improvement of this research, as well as recommendations for future research on this topic.

My research draws from two distinct sources of data. The first will serve as a demonstrative element: the burn trauma experiment. The experiment records the processes of burn trauma 
at a macroscopic level. In the methods section I will describe my analysis process and my experimentation methods. In the burn trauma experiment section are included photographs from this experiment process showing scorching, charring, muscle contraction, and calcination. Accompanying the photographs are descriptions of the processes that are occurring. The second source of data is the existing literature on the topic of burn trauma. The experts that I discuss have provided research and case studies on burn trauma. These experts are working to develop standards of practice for the field of forensic anthropology. This is a crucial process for any field, and it is necessary to understand how these processes develop and influence each other in order to address burn trauma cases with accuracy. I will use four theoretical perspectives to analyse this data and discuss it: 1) osteological theory, 2) biomechanics, 3) legal medicine, and 4) archaeological theory. This four-perspective approach is meant to provide a holistic view of the topic. Bioarchaeology, as the combination of biological anthropology and archaeology, is the theoretical framework from which this project has developed.

\section{Methodology}

Bioarchaeology as a subfield draws its strength from the combination of archaeology and biological anthropology. This subfield focuses on the skeletal indicators of trauma, specifically how they present and how they happen, and it is inherently multi-disciplinary: "Preserved skeletonized bodies/body parts can be analyzed as biological specimens, as artifacts, and as symbols" (Martin \& Herrod, 2015, p. 117). As anthropologists, we view the human body as the subjects of study in a multitude of ways, from historical artefact to evidence in a legal case, and this in turn requires us to draw from different disciplines and sub-fields to tailor our approach to the context. The complex nature of burn trauma requires this multidisciplinary approach. The work of anthropologists in the field of thanatology, or the study of death, can contribute to both historical and contemporary research. One notable example of this is the application of the discipline of anthropology to human rights work:

Forensic anthropologists, both physical anthropologists and archaeologists, contribute to human rights primarily by aiding in death investigation work. They join with physicians, odontologists, radiologists, and criminalists in revealing evidence of mass murder, genocide, torture, summary execution and political 'disappearances' (Burns, 1998, p. 66).

My bioarchaeological approach draws from four theoretical perspectives. Osteological theory and biomechanics fall into the field of biological anthropology and go hand-in-hand in describing the intrinsic and extrinsic factors of burn trauma. Osteology describes the internal composition of bone and soft tissue, while the field of biomechanics describes how these internal factors react to the extrinsic forces. Osteology focuses on the skeletal remains and the influences on and within that system. The field of burn trauma biomechanics focuses on how the process of burning acts as an extrinsic force. Archaeology is the subfield of anthropology, or in some areas of the world, a discipline of itself, that has a strong history of methods for recovering remains, including those that have been burned. Archaeological theory is divided into different sub-perspectives, including contextual archaeology and differential preservation. Contextual archaeology is imperative to the recovery of data: "If we wish to understand a type of artefact we must see it in the context of the site where it is found, the other artefacts, and seemingly unrelated aspects of material culture" (Dark, 1995, p. 38). The concept of differential preservation considers the relationship between the material that we see in the archaeological record and the material that does not survive: This is important in understanding "the limitations of our data and caution against interpretations which 
do not take its partial quality into account" (Dark, 1995, p. 47). Forensic medicine is the application of medical science to the practice of the law in relation to crime: This is specifically relevant to forensic cases, and for the practice of forensic anthropology. Forensic medicine is different than legal medicine in that the latter deals with the application of legislation to medical practice, whereas the former deals with the use of medical knowledge in the application of criminal law (Beran, 2010, p. 138). Forensic medicine focuses on trauma or damage, rather than the delivery of medical care (Beran, 2010, p. 139). When remains are found and collected in a criminal context, a medical expert can utilize their knowledge to gather data from the remains, including information regarding the sex, age at death, and any pathologies or trauma that may be present.

This project combines the research on the processes of burn trauma with the research on recovering burned human remains. To do this I build on the subfield of bioarchaeology, drawing on theoretical perspectives from within the social science and medical fields. I explain these perspectives and how they work together in forensic anthropology. I discuss leading research in the field of burn trauma and highlight key arguments that pertain to recovering and analysing burned human remains in forensic and archaeological contexts. The experiment demonstrates the various processes of burn trauma through a series of photographs. The modifications present in the experiment are compared with those described in the literature. I discuss the individual factors of burn trauma and how they interact, and their significance to forensic anthropology and bioarchaeology. I argue that a better understanding of the biochemical processes of burn trauma will enable forensic anthropologists to more effectively recover and document burned remains. I also argue that these processes result in significant structural changes that have substantial impact on the size, weight, morphology, and structural integrity of the remains that can make recovery, transport, and analysis of the remains difficult. Burn trauma research is imperative to the field of forensic anthropology due to the complex nature of this type of trauma. Trauma caused by extreme heat is prevalent: many events, whether accidental, environmental, or forensic, can all result in burn trauma. Whether archaeological or forensic, remains subjected to burn trauma require a different approach than those subjected to any other type of trauma. A multidisciplinary approach is necessary to the study and recovery of thermal trauma: The biochemical nature of this trauma is countered by the cultural and funerary influences, and this requires a holistic approach to fully understand what is involved. In the conclusion, I summarize my argument and make some suggestions for the improvement of this research, as well as recommendations for future research on this topic.

\section{Methodological Approach}

I approached this project from two distinct angles. The first was through a two-part experiment consisting of three open-air burns over two days. The experiment was documented with photographs: Each photograph was accompanied by a temperature and description. This allowed me to match the processes that were demonstrated through this experiment with the processes described in the literature. This experiment process is useful in that it provides visual evidence of the different burn trauma processes, rather than simple description. These burns effectively demonstrated these processes and how the different factors of burn trauma interact. The second methodological approach is a literature review: I gathered data on the specific processes of burn trauma and the implications for the profession of anthropology, archaeology, and forensic medicine. This is explored in the discussion section. I focused on the individual burning processes that are shared in the literature, the evidence of their occurrence, and the implications for recovery by these experts. I now combine these two sources of data to discuss the role of the field of anthropology in approaching burned human remains. 


\section{Methods}

This project draws upon two major sources of data: scholarly literature and data gathered from a burn trauma experiment. The literature comes from a diverse range of disciplines, including archaeology, forensic medicine, academic press, and forensic science. This allows me to look at the issue of the recovery of burned remains from a variety of perspectives, from the diverse range of professions that deal with the topic. The topics of the sources range from addressing physicochemical changes, and their resulting modifications, to archaeological excavation and recovery techniques. I use osteological theory to address the intrinsic factors of bone and soft tissue that are affected by burn trauma. An example of this is the reaction of the different components of bone: the calcium hydroxyapatite crystals, the material that makes bones brittle, expand, while the organic material, including the collagen that makes bone flexible, burn away (Waterhouse, 2013b, p. 1112). This approach comes from the field of biological anthropology. The biomechanics of burn trauma includes the biomechanics of fire: This approach addresses how fire and burn trauma works, and why this is important to the disciplines of archaeology and biological anthropology. With forensic medicine I show how this topic is applicable to forensic anthropology casework in a contemporary context. Finally, I demonstrate how this topic is relevant to archaeologists. For example, archaeologists deal with cremations in different historical contexts, including burials and cannibalism. This four-perspective approach builds upon work done by Dupras et al. (2012), Haglund and Sorg (2002), and Schmidt and Symes (2015), all of whom argue for continued development and refinement of methods and techniques in the field, and for team and interdisciplinary approaches to fatal fire scenes. I also draw upon the works of Shipman et al. (1984), Waterhouse (2013a, 2013b), and Ubelaker (2008) in reference to the intrinsic factors of bone and soft tissue and the processes of burn trauma. The experiment is used to demonstrate the various processes and show evidence of the descriptions found in the literature. The experiment is documented through photography and these Figures will be used as an illustrative tool.

\section{Theoretical Perspectives}

This four-perspective approach is valuable because it addresses the range of relevancy into which burn trauma falls. Osteological theory, the biomechanics of burn trauma, forensic medicine, and archaeological theory combine well to address the topic of the thermogenic modifications caused by burn trauma. The human skeleton is a useful tool in the diagnosis of disease, cause of death, and behaviour in life. An expert well versed in human osteology can use growth patterns, pathological, thanatological, and taphonomical processes, andss environmental conditions to read a set of remains and determine different factors. These factors can include sex, age at death, any diseases present, cause of death, and deposition processes. As the scientific study of death thanatology can include causes of death, reactions to death, even funerary practices. The field involved in reading the skeleton is osteological theory. Taphonomy is the study of the processes that occur after death. From this perspective we can gain a strong understanding of the intrinsic composition of bone, which will help us understand how bone will react to thermal trauma. This allows us to approach a set of burn remains with the ability to read the result and describe the burning event. While osteological theory allows us to understand the intrinsic composition of bone, the biomechanics of burn trauma are important to understand as the extrinsic factors that are causing changes in the bone.

Forensic medicine falls under forensic science, which is the application of scientific disciplines to the judiciary system. Forensic medicine is the application of medical training, expertise, and knowledge to legal cases and research. This can require the expert in the field to testify in court. The medicinal disciplines, such as human physiology and pathology, are invaluable in the 
assessment of human remains. Archaeological theory is a beneficial source of tools that can be, and have been, utilized for forensic anthropology. The discipline of archaeology is constructed of several theoretical branches, including experimental and contextual archaeology, which can inform the recovery and interpretation of burned human remains. These four theoretical perspectives inform my discussion of the data in the following sections. I demonstrate how these perspectives are relevant to the topic of recovering and analysing burned human remains in the discussion and conclusions sections below.

\section{Data}

This project attempts to combine a number of methods to create a robust analytical approach. I use descriptive data collection in the form of photographs, as well as statistical data in the form of the temperature of both the fire and the specimen. The literature review, drawn from scholarly sources, will provide the experiment with a practical context and historical framework. This project draws from both biological anthropology and archaeology. Forensic anthropology is a subfield of biological anthropology and there is a strong relationship with archaeology in that they both often deal with the evidence of human life from what is left behind. Burned human remains are not exclusive to forensic anthropology: Burning has been a common method of disposing of human remains and is recognizable in the archaeological record as well. In essence, I explore answers to the following questions:

1. What happens when remains are subjected to burn trauma?

2. What happens to the skin, fat, muscles, and connective tissues?

3. What happens to the bones?

4. What does calcination mean, and how do calcined bones react to handling during recovery?

It is important to understand how these processes work to be able to recognize them from the evidence that they leave behind. I expected to see predictable changes in morphology, structural integrity, and existing mass during the burning experiment. I also expected to see a strong relationship between forensic and archaeological approaches to the recovery of burned human remains. Both of these expectations were met by the data.

\section{Literature Review}

This section discusses the body of literature published by archaeologists and biological anthropologists on burned human remains. It focusses on the processes of burn trauma and the evidence they leave behind, specifically examining what the processes that we are looking at are, and how they advance. Several experts, including Rogers (2009), Schmidt and Symes (2015), and Ubelaker (2008) have addressed that issue in a number of ways. Some of the examples that are used by the experts I reference here utilize case studies of actual fatal fire scenes. Fire can cause significant damage when introduced to fleshed remains, and human bone reacts in predictable ways when introduced to thermal trauma. According to Figueiredo et al. (2010), there are two phases that bone goes through during the burning process: organic and inorganic. At $500-650^{\circ} \mathrm{C}$ the organic phase has passed, meaning that the organic elements of the bone have been essentiallye away (Figueiredo et al. 2010, p. 2384). The authors notice three distinct weight change events over the burning event: below $200^{\circ} \mathrm{C}$, between $220-600^{\circ} \mathrm{C}$, and between $700-900^{\circ} \mathrm{C}$. This is due to the dehydration of the samples, including the removal of the organic materials collagen and water, 
and in the last phase, it is due to "the release of $\mathrm{CO}_{2}$ from the apatite lattice, due to carbonate decomposition" (Figueiredo et al., 2010, p. 2386). After reaching a temperature of $600^{\circ} \mathrm{C}$, the specimens become protein-free, which may limit analysis (2010, p. 2391). This means that the bone is breaking down at a chemical level in phases throughout the burning process. The calcium hydroxyapatite crystals, the material that makes bones brittle, expand and take over, while the organic material, including the collagen that makes bone flexible, cook away: Essentially, the bones crystallize (Waterhouse, 2013b, p. 1112). The result of this crystallization is an increase in fragility and a decrease in structural integrity: The texture is powdery, flaky, fragmented, and dry, so careless handling and even wind can cause damage. The colour ranges from white to blue to grey, and so can be mistaken for other materials, including bleached plant material.

Table 1: Shipman et al. 1984: 314

\begin{tabular}{|c|c|c|}
\hline Stage & Temperature & Description \\
\hline 1 & $20-185^{\circ} \mathrm{C}$ & Normal texture; undulating and intact surface \\
\hline & $185-285^{\circ} \mathrm{C}$ & $\begin{array}{l}\text { Granular, rough surface; pores and fissures, } \\
\text { intact surface }\end{array}$ \\
\hline & $285-440^{\circ} \mathrm{C}$ & $\begin{array}{l}\text { Glassy, smooth surface; vitrified; polygonal } \\
\text { cracking in subchondral bone caused by dehydration; } \\
\text { cracks between } \\
\text { vascular canals; defined edges of plates }\end{array}$ \\
\hline & $440-800^{\circ} \mathrm{C}$ & Spectrum: granular to frothy bone surface \\
\hline & $800-940^{\circ} \mathrm{C}$ & $\begin{array}{l}\text { Granular particles melt; edges soften as and } \\
\text { smooth out }\end{array}$ \\
\hline
\end{tabular}

As the bones lose collagen, the ability of the bone to adjust to morphological changes reduces with its elasticity, and the pre-burning collagen content of the bones will in turn affect the postburn result (Waterhouse, 2013a, p. 409.e2). Shipman et al. (1984) provide an overview of the thermogenic modifications of colour, structure, size, and shape. The colour changes are predictable: "hue starts in the yellow range, passes through reds and purples, and changes to diverse neutral hues above about $400^{\circ} \mathrm{C}^{\prime \prime}$ (Shipman et al., 1984, p. 312). The authors also provide a useful guideline for the stages of these factors by temperature, which are summarized in Table 1, which shows that bones undergo predicable and observable modifications. According to Ubelaker (2008), at $700^{\circ} \mathrm{C}$ overall shrinkage is observed, intensified at $800^{\circ} \mathrm{C}$, and halts at $900^{\circ} \mathrm{C}$. Between $800-1400^{\circ} \mathrm{C}$ new calcium hydroxyapatite crystals develop, with some of the crystals exhibiting fusion starting at $1000^{\circ} \mathrm{C}$ (p. 3).

The extrinsic factors in burn trauma vary from one situation to another. Symes et al. describe the three reliable factors in the diagnostic process of recovery: body position and tissue shielding; Colour changes; and burned bone fracture biomechanics (2015, p. 34). For the first factor, muscle contraction causes pugilistic posture in which joints flex, resulting in shielding of some of the soft tissue and bones within those joints. The soft tissue and bone that is more exposed will burn first and there will be more damage, whereas the protected soft tissue and bone caused by greater tissue depth and pugilistic posture will be less likely to burn as completely as more exposed areas. The authors discuss colour changes as a diagnostic tool: colour changes as the process of burning advances, and this can be used to establish the direction of the fire and the distribution of exposure. They also describe seven fracture patterns caused by burn trauma biomechanics: 1) longitudinal, 2) step, 3) transverse, 4) patina, 5) splintering and delamination, 6) burn line fractures, and 7) curved transverse fractures (Symes et al., 2015, p. 46-47). Each of these fracture patterns is the result of different biomechanical processes. For example, the patina fracture patterns closely resemble the 
cracking on the surfaces of old paintings: This is likely due to a consistent shrinkage across the surface of the bone and the incineration of thin, protective soft tissue layers (Symes et al. 2015, p. 46). Figure 2 shows patina fracturing in the calcined bone of the specimen used in the November 2015 experiment run (see p. 29).

Funerary cremations are often elaborate events, but they may leave little to no archaeological evidence (Pearson, 2008, p. 7). Pearson offers guidelines for the excavation of cremations, both pits and pyres: The burial "should be sampled by flotation, wet-sieved through a $2 \mathrm{~mm}$ mesh to recover charred plant and wood remains as well as small pieces of bone" (2008, p. 201). Pearson also suggests bandaging cremations that are buried in containers to be lifted and removed for excavation and analysis (2008, p. 202). Dirkmaat (2002) demonstrates the necessity of thorough documentation in the context of fatal fire victims:

During the post-mortem investigation, wire from an underwire bra associated with the remains was recovered. However, the nature of the association (worn by the individual at the time of death?) was indeterminable, because the in situ location of the artefact was not noted during recovery (p. 457).

In this case, the remains were so fragmented and burned that the wire was no longer attached to any cloth, or connected to the remains. As such, the context was lost, and the origin of the wire, which could have been worn by the victim or used as an instrument of trauma, was unknown. Dirkmaat also notes the importance of interdisciplinary approaches to fatal fire scenes, specifically in employing archaeological expertise in the recovery of burned remains: "nonarchaeological recovery methods commonly employed almost invariably lead to loss of both osteological material... and contextual data" (2002, p. 458). Interestingly, calcined bone preserves better than non-calcined bone in acidic soil (Pearson, 2008, p. 7).

Fairgrieve (2008) recognizes the importance of bone histology on how it will react in a burning environment. The inorganic structure of bone is calcium hydroxyapatite which is a type of calcium phosphate. Fairgrieve notes that there is a high affinity between the calcium and phosphate ions and this results in a stable structure (2008, p. 131). This is what gives bone its strength and hard texture. The organic matrix is made up of collagens (a structural protein) and other proteins, and this is what gives bone its flexibility and the ability to react to changes in size, shape, and weight over time (Fairgrieve 2008, p. 132). Removing the organic matrix through burning is what causes fracturing and calcination, and so it is what causes the most damage. When the muscles contract, the now brittle and inflexible bone fractures rather then adjusts to the new shape. Thompson (2015) recognizes the importance of heat-induced changes in the crystal structures of bone in regards to addressing the complex relationship between the burning context and the consequent changes. Thompson does this through the analysis of the crystal structure of bone, arguing that the use of crystallinity measures in burned bone has implications for forensic anthropology, medical practice, archaeology, and even the processing of meat product waste $(2015, \mathrm{p}$. 324). The crystal structure of bone, $\mathrm{Ca}_{10}\left(\mathrm{PO}_{4}\right)_{6}(\mathrm{OH})_{2}$, reacts in predictable ways, resulting in thermogenic modifications, when exposed to burn trauma. These reactions are predictable through laws of chemistry, much like the reaction of vinegar and sodium bicarbonate. Thompson argues that there is a need for a greater understanding of the differing influences on heat-induced crystallinity changes, and for improvement in the accuracy and reliability of the methods that are used in the study of these changes (2015, p. 333). Thompson describes these changes as part of the diagenetic process: The organic and inorganic components of bone are influenced and changed by the environmental conditions in which it is situated, including heat and fire (2015, p. 333-334). Diagenesis is the process of alteration in the proportions of organic and inorganic elements.

The analysis of the changes in the isotopic composition of bone is a useful method in the 
assessment of burned remains. Schurr et al. (2015) use $\delta^{15} \mathrm{~N}$ and $\delta^{13} \mathrm{C}$, the measures of the ratio of stable isotopes, as quantifying factors in the analysis of burned remains. Exposure to burning raises the $\delta^{15} \mathrm{~N}$ values and lowers the $\delta^{13} \mathrm{C}$ values (Schurr et al. 2015, p. 112-113). Therefore, due to the diagenetic effects of the burning processes, burned bone is not viable for molecular or chemical analyses, or radiocarbon dating (Pearson, 2008, p. 202). This limits the range of options that an archaeologist can draw from during their analysis of excavated burned remains. Another important assessment method of cremated remains is the analysis of bone colour. Bone colour during and after a burning event will be determined by a number of factors, including duration of exposure, anatomical location, accelerants, temperature, and environment. However, there are specific stages that remains will progress through: scorching, charring, calcination, and incineration. While colour alone cannot tell us at what temperature bone has been burned, it can be used to indicate the general temperature range (Shipman et al. 1984, p. 314). Devlin and Herrmann ran analyses of burn remains to determine patterns of bone colour. They found subtle differences between the resulting colour of core and appendicular elements when remains were exposed to temperatures above $300^{\circ} \mathrm{C}$ : Skull and core elements end up more white with traces of yellow, while appendicular elements are more blue and grey $(2015$, p. 137). This tells us that the appendicular skeleton progresses further along the burning processes than the core elements. Bennett (1999) reminds us that, while burn trauma is often the result of intentional activity or accidents, such as crashes, explosions, or criminal activity, incidental burning of bone is often possible. According to Alunni et al. (2014), most often we see severe damage, but not necessarily calcination, and cremations on wooden pyres are more common in archaeology than forensic anthropology. As a result, forensic anthropological literature does not focus on cremations of this kind. This is a gap in the literature that should be concentrated on: These events still happen, and this project seeks to contribute to the literature that is intended to address this gap.

\section{Burn Trauma Experiment}

This section describes the experimental study of how different tissues, including both soft and hard tissues, react to thermal trauma, specifically burn trauma. The results of this experiment provide a discussion on what evidence is left behind by burn trauma, and how that evidence can be retrieved from the site. The experiment consisted of two timed burns on wood fire pyres in an outdoor setting using the legs of sus scrofa domesticus, or domestic pig, including all soft and hard tissues. It is common in the field of forensic anthropology to use pig specimens as a proxy for human remains in experiment. While using non-human remains has its drawbacks, namely that human remains are particular in molecular structure and morphology, it can be useful in researching taphonomic processes. Human remains can be difficult, expensive, or in some countries, impossible to obtain for research. The photographs show specific processes on a macroscopic level. It is important to note that this experiment is demonstrative only: This experiment did not produce specific data regarding burn trauma. Rather it served an important purpose of providing illustrative evidence of the processes that are already well recorded in the literature. The chart below shows the general outline for the experiment, performed on two separate occasions. I used a digital thermometer in order to be able to accurately measure the temperature of the fire and the specimens from a safe distance. Below this chart is a series of figures from this experiment with their associated descriptions.

The photographs below were taken during the first run of the experiment in November 2015. This run took five hours from beginning to end and used Specimen A. The weather was overcast with low wind. The included photographs are a small selection from this run of the experiment. This experiment consisted of a single fire and specimen. The pyre consisted of a layer of coal, 
Table 2: Burn Experiment Guideline

Specimens: $\quad$ Limbs of sus scrofa domesticus: 3 specimens

Method: $\quad$ Open air burn on wood and, charcoal fire, no accelerants

Documentation Photography, data sheets

Time: $\quad$ Approximately 2-5 hours, until calcination

Location: Open field

paper, and then wood. Once the fire was lit and the wood had caught, the specimen was placed on the pyre. The specimen was photographed throughout the burning process, and most photographs were accompanied by a time, digital temperature reading, and description. The temperature was measured with a digital laser thermometer to allow safe and accurate temperature reading. Once the specimen had reached calcination, it was removed from the fire and allowed to cool before transportation. The calcined bone experienced significant damage during transportation. Dr. Ranald Donaldson assisted in the documentation process.

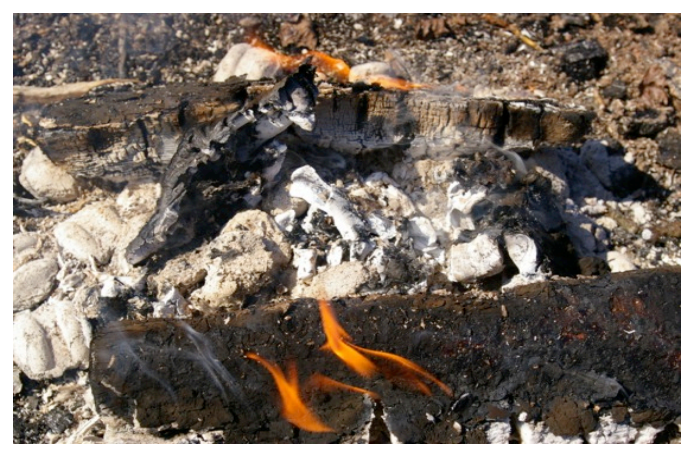

Figure 1: Specimen 1. Specimen temperature: $650.2^{\circ} \mathrm{C}$. Fire temperature: $>900^{\circ} \mathrm{C}$. Time: $\mathrm{T}+60$. Efford 2016.

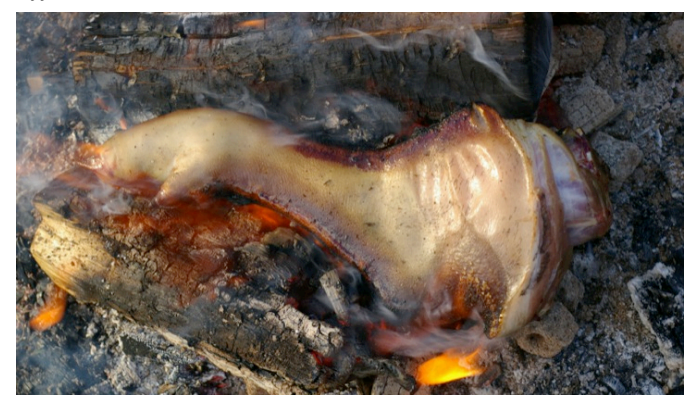

Figure 3: Specimen A. Specimen temperature read $199.0^{\circ} \mathrm{C}$. Efford 2015.

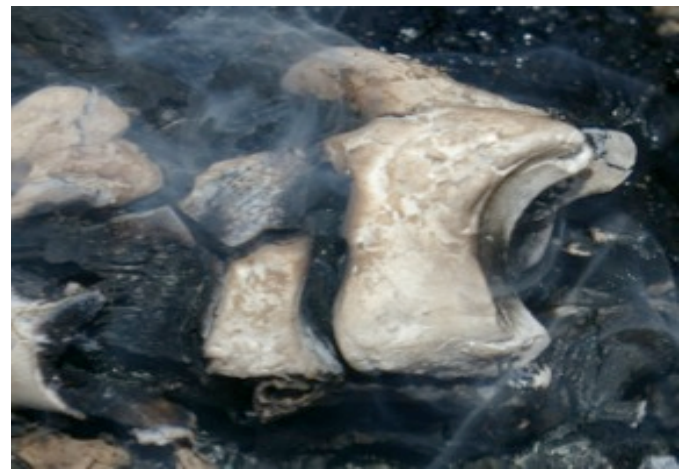

Figure 2: Calcined bone showing patina fracturing. Efford 2015.

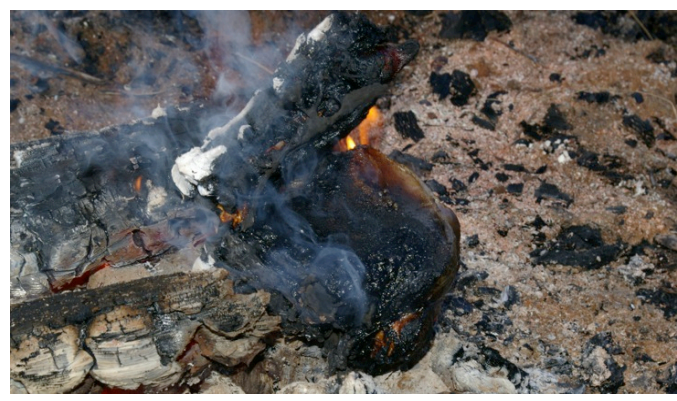

Figure 4: Specimen A. Specimen temperature $460.0^{\circ}$ C. Efford 2015.

In Figure 3 we see the initial stages of burn trauma in which the fatty layers are melting and the underside of the specimen is showing scorching and charring. The skin and surface muscles are contracting along facial planes. In Figure 4 muscle contraction is in process: This is the beginning of pugilistic posture. Significant charring is present and calcination is present on the side most 
exposed to fire. We can see a range of effects from scorching to calcination in this Figure. In Figure 5 the specimen shows significant charring and the fat layers are melting into the fire. Some evidence of calcination is present. This is after the muscle contractions dislocate the ankle joint: the foot is seen here touching the lower leg. This is an example of pugilistic posture.

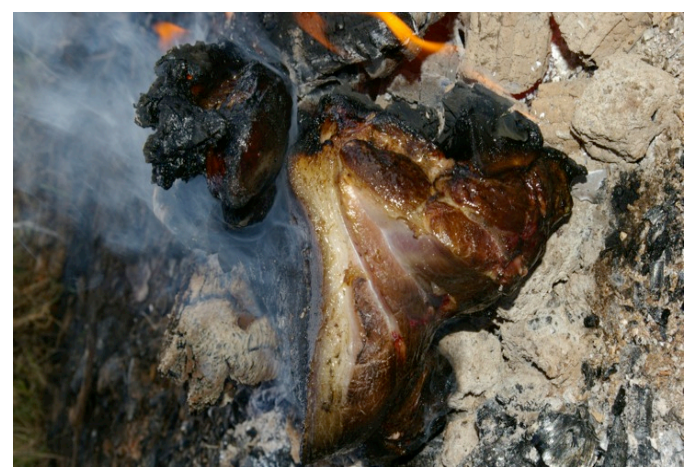

Figure 5: Specimen A. Specimen temperature: $461.7^{\circ} \mathrm{C}$. Fire temperature read over $900^{\circ} \mathrm{C}$. Efford 2015.

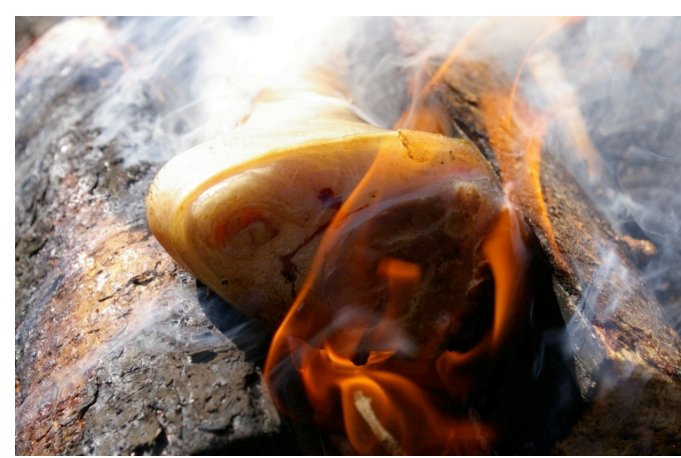

Figure 6: Specimen 1. Specimen temperature: $235.6^{\circ} \mathrm{C}$. Fire temperature read $>900^{\circ} \mathrm{C}$. Time: T+14. Efford 2016.

The second run of the experiment was performed in April 2016. This run took 2 hours from start to finish. This accelerated time frame seems to be due to the clear weather and increased wind speed. Two specimens, 1 and 2, were used on two separate wood and charcoal pyres. Each pyre was prepared in the same way as the one used in the first run of the experiment and the specimens were placed on the fire only once the wood had caught. The specimens were photographed and the respective temperatures and times were recorded throughout the burning process. A digital laser thermometer was used for this experiment run as well. The photographs included in this paper are a selection from the entire photographic data set collected from this run. The entire collection of photographs for this experiment is available upon request to the author. Time $(\mathrm{T})$ is used as the time at which the specimens were placed on the fires, and added time is in minutes (e.g. $\mathrm{T}+10$ is the time specimens were placed on fire plus 10 minutes).

In Figure 6 we see the initial stages of burn trauma in Specimen 2: scorching and charring. The blood and fat has started to melt into the fire, and the surface layers of the specimen have started to separate from the bone and deep muscle layers, along the facial planes. Already the specimen is exhibiting changes in appearance. In Figure 7 we see Specimen 1 advancing through the charring stage: there is evidence of charring almost completely surrounding the specimen and the surface that is directly exposed to the fire is starting to exhibit calcination. The fat layers are continuing to melt into the fire. The skin is charred and is peeling back from the subcutaneous layers of soft tissue. At the exposed bone edge, the cut proximal end of the bone, we can see the beginning of calcination.

In Figure 8 we see significant charring and the gross size of the specimen has reduced as the soft tissue has burned away. There is still a significant amount of organic material present here. Figure 9 shows that the soft tissue of Specimen 1 is melting and dripping into the fire. The charring is extensive and calcination is increasing. The processes of burn trauma have started to increase in pace: As the organic materials are burned away, the inorganic phase starts to take over. In Figure 10 we can see that the contraction of the posterior muscles of Specimen 1 is significant. Charring has reached the side of the specimen not directly exposed to fire. At the proximal end of the specimen the skin has peeled back and has exposed the subcutaneous soft tissue layers to 


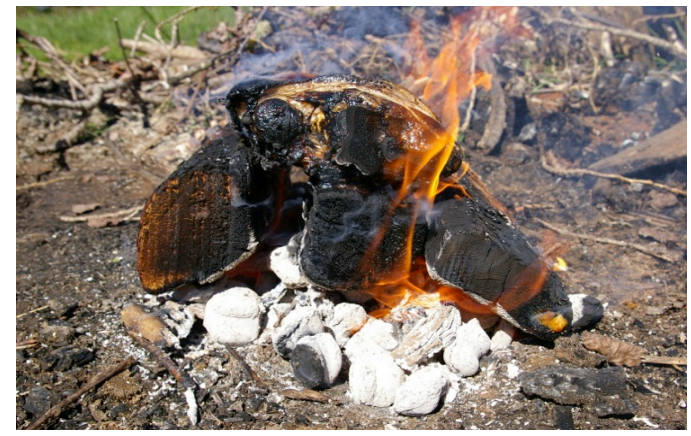

Figure 7: Specimen 2. Specimen temperature read $259.5^{\circ} \mathrm{C}$. Time: $\mathrm{T}+10$. Efford 2016 .

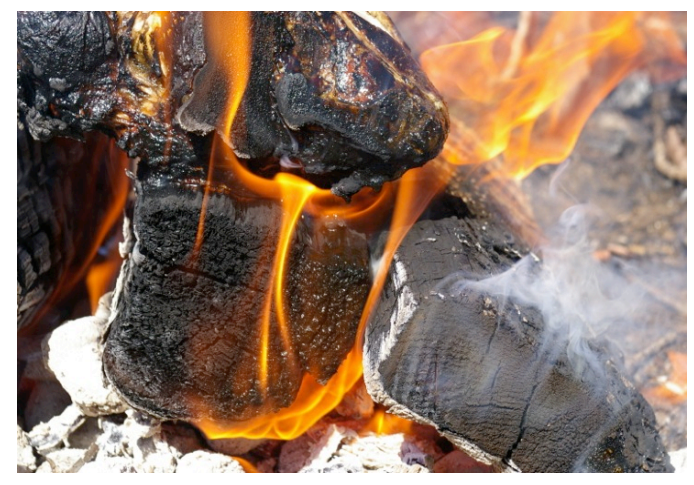

Figure 9: Specimen 1. Specimen temperature: $491.1^{\circ} \mathrm{C}$. Fire temperature: $>900^{\circ} \mathrm{C}$. Time: $\mathrm{T}+19$. Efford 2016.

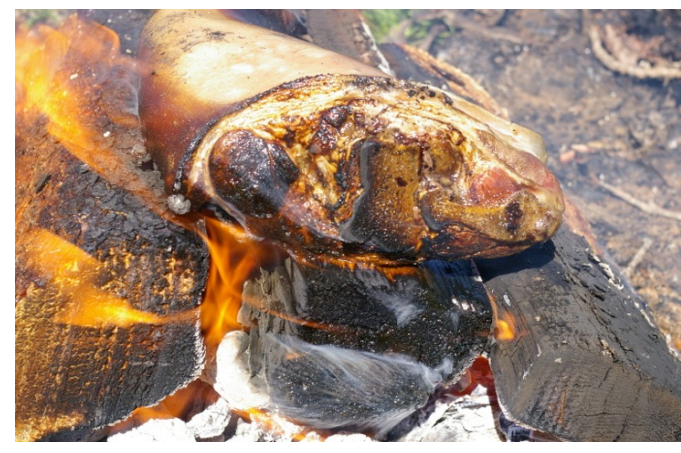

Figure 8: Specimen 1. Specimen temperature read $491^{\circ} \mathrm{C}$. Fire temperature read $>900^{\circ} \mathrm{C}$. Time: T+14. Efford 2016.

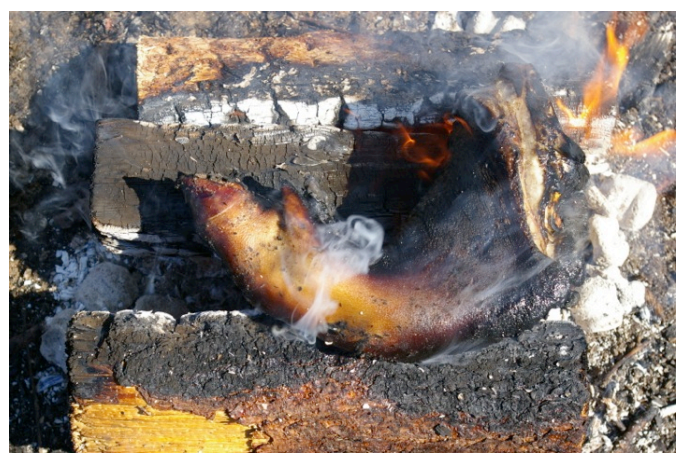

Figure 10: Specimen 1. Specimen temperature: $379^{\circ} \mathrm{C}$. Fire temperature: $>900^{\circ} \mathrm{C}$. Time: $\mathrm{T}+23$. Efford 2016.

the heat source. In Figure 11 below, the calcination of Specimen 2 has become noticeable. The charring is significant and has reached the side of the specimen not directly exposed to fire. The skin has peeled back in this specimen as well.

In Figure 12 the charring has surrounded Specimen 2. The soft tissue has started to boil on the surface that is not directly exposed to the fire. The side that is directly exposed is showing calcination. The overall size of this specimen appears to have reduced. In Figure 13 we can see that the muscle contraction is significant. The soft tissue is boiling on the surface of Specimen 1. This specimen is completely charred and the overall size appears to have reduced significantly due to the muscle contraction and loss of soft tissue. Figure 14 shows that calcination of Specimen 2 is complete, the specimen has fragmented transversely, and many of the bones have fragmented into several pieces. The fragmented bone is a very light white-blue colour and ranges in size from complete bone to powder. The cream-coloured objects in this Figure are coals. As we can see from these Figures, the literature accurately describes the burn trauma processes, how they occur, and at what temperature we can expect to see the changes caused by those processes.

In Figures 7 through 14 we see a progression of the burning process. The images show a range of stages, from charring through to calcination. It is important to note the differences in burning rates between the two burning events. The first event took much longer than the second, and this 


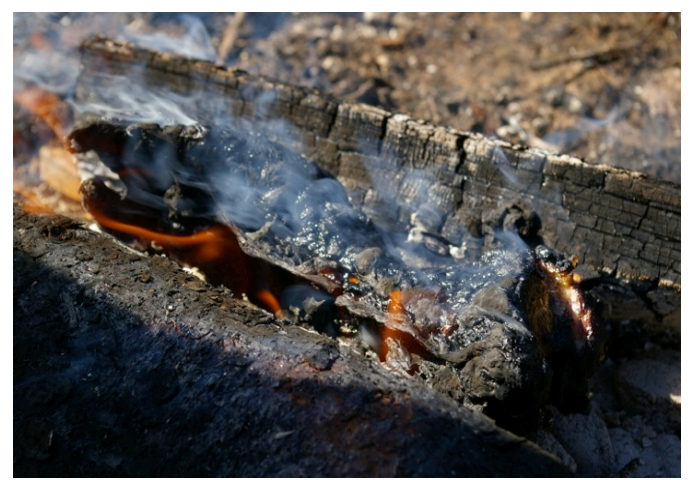

Figure 11: Specimen 1. Specimen temperature: $502.7^{\circ} \mathrm{C}$. Fire temperature: $>900^{\circ} \mathrm{C}$. Time: $\mathrm{T}+30$. Efford 2016.

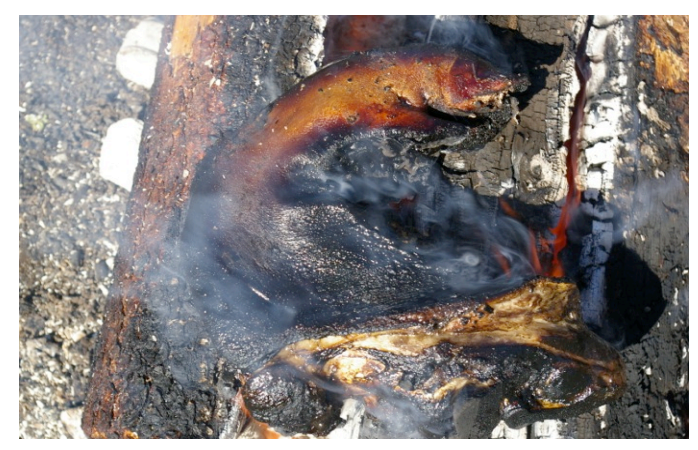

Figure 13: Specimen 2. Specimen temperature: $553.9^{\circ} \mathrm{C}$. Fire temperature: $>900^{\circ} \mathrm{C}$. Time: $\mathrm{T}+39$. Efford 2016.

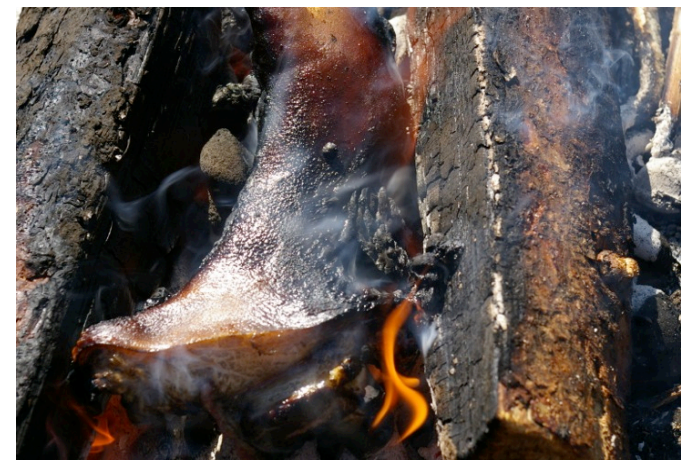

Figure 12: Specimen 2. Specimen temperature: $480.2^{\circ} \mathrm{C}$. Fire temperature: $>900^{\circ} \mathrm{C}$. Time: $\mathrm{T}+24$. Efford 2016.

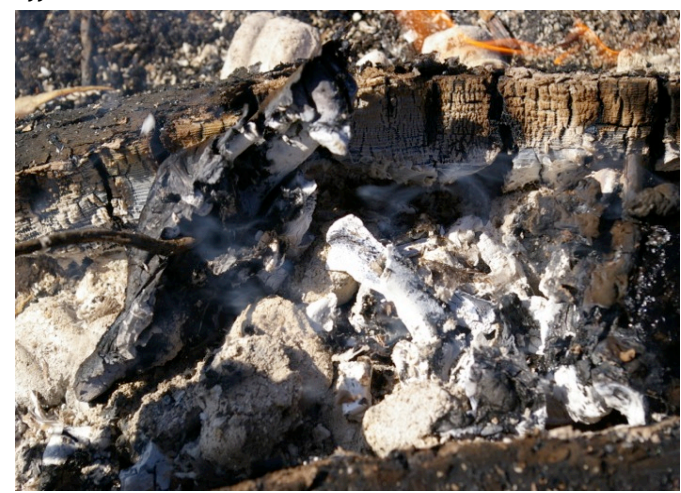

Figure 14: Specimen 2. Specimen temperature: $649.1^{\circ} \mathrm{C}$. Fire temperature: $>900^{\circ} \mathrm{C}$. Time: $\mathrm{T}+69$. Efford 2016.

is likely due to the weather. In November the day was cold and overcast and the ground was not dry. In April the temperature was higher and the wind speed accelerated enough to feed the fire. This is a reminder that there are many factors in burn trauma cases that are important to include in the analysis of the trauma.

\section{Discussion}

In order to understand what is seen in the archaeological and forensic records in regards to burn trauma, we have to understand what specifically constitutes burn trauma, when and where we see it contextually, and why it is significant. We have to understand the biochemical processes of burn trauma, and how the results of those processes influence recovery methods. Based on the data presented above, it is clear that the processes of burn trauma result in thermogenic modifications that cause significant variation from the original bone. It is also clear that the results of these modifications, namely fragmentation and calcination, require calibrations to the methods of recovery and analysis. An increase in temperature and duration will result in a greater number of changes, and more significant change. Methods of recovery and analysis are in a continuous 
process of refinement, and experts work in teams.

Forensic anthropology is a relatively new discipline. It is currently undergoing the long process of creating a toolkit of standards and methods to be employed in the field. The discipline can benefit from drawing upon the two sub-disciplines of anthropology that helped create it, biological anthropology and archaeology: this places it firmly in the realm of bioarchaeology. These two disciplines have pools of knowledge that can be utilized in forensic anthropology in a number of ways and this research shows one such context. Forensic medicine is another use of a discipline in forensic contexts: in this case, medical knowledge is applied to legal cases. Many medical doctors who work with legal cases fall under the umbrella of forensic anthropology if they interpret the medical elements of the case while keeping the relevant cultural influences in mind. The discipline of forensic anthropology will benefit from the range of experts, from anthropologists to doctors, because that range allows the discipline to approach the analysis of human remains in a forensic context from all possible angles. These cases are complex and a narrow; an individualistic approach will not suffice. Experts in forensic anthropology who are involved in these cases may be called as a witness in court. This means that they will have to testify regarding their findings, and will be required to support their expertise in the field. All of their findings must be reported to the court and their testimony may be weighed in the court's decision. Table 3 summarizes much of the data discussed above, and demonstrates the relationships between these different factors.

Table 3: Data Relationships. Efford 2016

\begin{tabular}{|c|c|c|c|c|c|}
\hline Temperature & Composition & Shrinkage & Texture & Weight & Soft tissue \\
\hline $100^{\circ} \mathrm{C}$ & \multirow{5}{*}{$\begin{array}{c}\text { Organic } \\
\text { phase: } \\
\text { organic } \\
\text { material still } \\
\text { present }\end{array}$} & \multirow{7}{*}{ Absent } & $\begin{array}{c}\text { Intact } \\
\text { surface }\end{array}$ & $\begin{array}{l}1^{\text {st }} \text { weight } \\
\text { change }\end{array}$ & Scorched \\
\hline $200^{\circ} \mathrm{C}$ & & & Granular & \multirow{5}{*}{$\begin{array}{c}2^{\text {nd }} \text { weight } \\
\text { change }\end{array}$} & \multirow{5}{*}{ Charred } \\
\hline $300^{\circ} \mathrm{C}$ & & & Glassy, & & \\
\hline $400^{\circ} \mathrm{C}$ & & & fractures & & \\
\hline & & & \multirow{5}{*}{$\begin{array}{l}\text { Progression } \\
\text { from } \\
\text { granular to } \\
\text { fractured to } \\
\text { melting }\end{array}$} & & \\
\hline $500^{\circ} \mathrm{C}$ & \multirow{5}{*}{$\begin{array}{l}\text { Organic } \\
\text { material } \\
\text { cooked } \\
\text { away: } \\
\text { inorganic } \\
\text { phase }\end{array}$} & & & & \\
\hline $600^{\circ} \mathrm{C}$ & & & & & Range: \\
\hline $700^{\circ} \mathrm{C}$ & & \multirow{3}{*}{ Present } & & \multirow{3}{*}{$\begin{array}{c}3^{\text {rd }} \text { weight } \\
\text { change }\end{array}$} & Charred to \\
\hline $800^{\circ} \mathrm{C}$ & & & & & Calcined \\
\hline $900^{\circ} \mathrm{C}$ & & & Melting & & Calcined \\
\hline
\end{tabular}

The factor of duration, or time, while important, is not included because it would not change the other factors, only speed them up or slow them down. Weight was not recorded for this experiment. It is important to note that between $600-700^{\circ} \mathrm{C}$ there is generally no weight change. The temperatures and their corresponding modifications that are shown below are based on the literature review discussed above, and are not exhaustive. These relationships are complex and this table should be regarded with this in mind. Here we see some of the specific changes that are caused by burn trauma processes. These changes were also seen in the photographs above: The experiment shows us that the processes and expected changes are predictable and the literature provides us with accurate expectations as to what to see and when we will see it. 
The data supports a three-phase progression of thermogenic modifications that correspond directly to temperature. As the temperature increases, different reactions are initiated: Organic material starts to burn away gradually, shrinkage is eventually introduced, and the texture changes as the microstructure of the bone transforms. Each phase corresponds to an adjustment in weight: this is directly caused by a change in bone composition. The collagen and water make up the weight that is lost through the burning process, and, in the third phase, the carbonate decomposes. At approximately $500^{\circ} \mathrm{C}$ the remains enter the inorganic phase, and as this organic material is lost, the charred remains calcine. The calcium hydroxyapatite, the inorganic material, expands and takes over at this stage. This material becomes brittle and does not adjust under bending, shrinking, and twisting pressures: Rather, it fractures. The organic material gives the bone its flexibility; without this, the muscle contractions on the indirectly exposed side of the remains can cause fractures on the exposed sides, which are at a more advanced stage in the cooking process. The changes represented in this table result in morphological changes; the consequence of these changes is a dramatic change in appearance, which will hinder the identification of the remains and possibly result in false diagnoses of cause and manner of death because any evidence of pre-existing trauma or pathologies may be concealed or removed. The changes in isotopic and molecular composition make it difficult to run standard archaeological tests for geographical origin and dietary information.

Burn trauma is subject to many variables that influence how the remains react to the exposure to the fire, and one of the most significant effects of burn trauma is that of fragmentation. This is an issue because the overall morphology is compromised. This fragmentation is caused by a breakdown in the structural integrity of the remains. Because overall morphology changes, our assessment of what we see will be drastically different than what we would have found if the remains had not been introduced to thermal trauma. Archaeologists have recognized the need for thorough in situ documentation of remains, the environment, and any associated evidence. This is necessary for the preservation of context, which is essential in both archaeological and forensic investigations. The concept of contextual archaeology approaches documentation from this perspective. The modifications in isotopic composition can have implications for the analysis of burned bone in that stable isotopes can be used to determine diet and geographical origin. Without the ability to analyse the stable isotopes of a set of remains, that eliminates another method of identifying the remains and possibly the context in which they are burned. With further research the study of how burn trauma progresses in different parts of the body could allow us to read body positioning, site formation, and differential burning patters with greater accuracy. Bone can be deposited in a grave or as part of a midden as waste, and if a fire is built on top of that deposition, that can cause incidental burning of the bone. Middens are food waste deposits that are important archaeological finds; they indicate, and give information about, human settlement and life. Burning is not always trauma: It can be a taphonomic process. It is important to avoid declaring trauma when it is possible that none occurred.

Anthropologists have the benefit of approaching the study of the human species from a number of different perspectives. Biologist anthropologists study the species from the biological, chemical, and evolutionary standpoint. Archaeologists approach the species from the perspective of death and the past. Forensic anthropologists combine scientific and cultural perspectives to gain a more holistic understanding of the data that they are gathering. This holistic approach to the human species gives us a strong foundation upon which to study trauma. 


\section{Limitations}

This research project addresses the only the specific research questions discussed in the above sections and is not meant to serve as an instructional manual for the recovery and analysis of burned remains. This research does not include an actualistic experiment that is meant to create new data on burned remains. The experiment described in this research is meant to demonstrate the various processes of burn trauma that have been discussed here. Domestic pig specimens are used to show what happens when fleshed remains are subjected to burn trauma on a macroscopic level, not on a microscopic or cellular level. In the future, this research could include more specimens for the demonstrative experiment, and an actualistic experiment that would serve to provide new data. Because the experiment was not designed to gather new data, weight was not recorded before or after the burning event. This would be beneficial in future experiments in order to illustrate the weight changes. However, the decrease in weight during burn trauma is well established and therefore the addition of this factor would not necessarily contribute new information to the discussion.

\section{Summary ANd Conclusion}

The processes of burn trauma and their resulting changes have been discussed, and the role of anthropologists in these cases has been addressed. The literature reviewed here is a sample from the leading expertise on the topic of burn trauma and allows us to understand how the professions are approaching these cases. The thermogenic modifications caused by burning have significant implications for the recovery and analysis of remains, notably the changes in weight, size, shape, composition, and structural integrity. It is imperative that forensic anthropologists understand the biochemical processes that result in these thermogenic modifications in order to successfully recover and analyse remains. This is why a bioarchaeological approach is useful for the context of burn trauma: The tool kit of the combined archaeologist and biological anthropologist provides a solid foundation upon which to discuss this complex topic. The training in archaeological survey and excavation, analysis of human remains, and knowledge of human physiology, biomechanics, and anatomy are all part of these toolkits that are valuable to forensic anthropologists. This project has only skimmed the surface of this topic, and further research into the cause and effects of burn trauma is important. We see burn trauma in a variety of contexts, including criminal, funerary, and accidental, and working on these cases can have national and international legal, as well as cultural, implications.

To conclude, burn trauma is becoming recognized as an important topic of forensic anthropology that is gaining the interest of experts in the field. Common recommendations are for team approaches to recovery and analysis and for photographic documentation. There is recognition of the delicate nature of the remains and the necessity for care in the handling and transport of those remains. The thermogenic modifications discussed here result in confounding factors that make it difficult to identify burned remains and to discover what happened. It is not feasible to approach burn trauma cases as individual researchers: These cases require experts from diverse fields to document, recover, and analyse the remains. The inclusion of weight in the recorded factors during experimentation would allow us to understand how the other factors that are discussed here are reflected in the weight of the specimens. Although the existing literature already recognizes that weight changes occur, comparing those changes to the other factors allows for a more complete picture. This is clear from table 3 in which the factors of burn trauma are laid out together. The bioarchaeological approach of forensic anthropology benefits from the combined experience of archaeologists, biological anthropologists, and medical experts who have a background in 
osteology and biomechanics. Each of these professions has their own pool of knowledge from which forensic anthropology can benefit. There is a need for experts in these fields to combine their respective toolkits to approach burn trauma cases, and forensic anthropology as a whole, with greater accuracy and productivity.

\section{REFERENCES}

Alunni, V., Grevin, G., Buchet, L. \& Quatrehomme, G. (2014). Forensic Aspect of Cremations on Wooden Pyre. Forensic Science International, 24(1), 167-172. http:/ /www.sciencedirect.com.ezproxy. library.uvic.ca/science/article/pii/S0379073814002345

Bennett, J. (1999). Thermal Alteration of Buried Bone. Journal of Archaeological Science, 26, 1-8. http:/ / firearchaeology.com/Bone iles / Bennett $_{1}$ 999.PDF

Beran, R. (2010). What is legal medicine - Are legal and forensic medicine the same? Journal of Forensic and Legal Medicine, 17(3), 137-139. http:/ / www.sciencedirect.com.ezproxy.library.uvic.ca/ science/article/pii/S1752928X09001590

Burns, K. (1998). Forensic Anthropology and Human Rights Issues. In Reichs, K. (Ed.), Forensic Osteology: Advances in the Identification of Human Remains. (pp. 63-85) Illinois, USA: Charles C. Thomas Publisher, Ltd.

Dark, K. R. (1995). Theoretical Archaeology. New York, USA: Cornell University Press.

Devlin, J. \& Herrmann, N. (2015). Bone Colour. In Analysis of Burned Human Remains. (pp. 119-137) Florida, United States: CRC Press.

Dirkmaat, D. (2002). Recovery and Interpretation of the Fatal Fire Victim: The Role of Forensic Anthropology. In Advances in Forensic Taphonomy: Method, Theory, and Archaeological Perspectives. (pp. 451-459) Florida, United States: CRC Press.

Dupras, T., Schultz, J., Wheeler, S.\& Williams, L. (2012). Forensic Recovery of Human Remains: Archaeological Approaches. Florida, United States: CRC Press.

Fairgrieve, S. (2008). Heat-Induced Alterations of Bone Microstructure. In Forensic Cremation: Recovery and Analysis. (pp. 131-140) New York, United States: CRC Press.

Figueiredo, M., Fernando, A., Martins, G., Freitas, J., Judas, F. \& Figueiredo, H. (2010). Effect of the Calcination Temperature on the Composition and Microstructure of Hydroxyapatite Derived from Human and Animal Bone. Ceramics International, 36, 2383-2393. http:/ / www.sciencedirect .com.ezproxy.library.uvic.ca/science/article/pii/S0272884210002683

Haglund, W. D. \& Sorg, M. H. (2001). Advanced in Forensic Taphonomy: Method, Theory, and Archaeological Perspectives. Florida, United States: CRC Press. 
Martin, D. \& Herrod, R. (2015). Bioarchaeological Contributions to the Study of Violence. Yearbook of Physical Anthropology, 156, 116-145. http:/ / onlinelibrary.wiley.com.ezproxy.library.uvic.ca/ doi/10.1002/ ajpa.22662/epdf

Pearson, M. (2008). The Archaeology of Death and Burial. Texas AEM University Press. Texas, United States.

Schmidt, C. W. \& Symes, S. A. (2015). The Analysis of Burned Human Remains. Florida, United States: CRC Press. http://www.sciencedirect.com/science/book/9780128004517

Schurr, M., Hayes, R., \& Cook, D. (2015). Thermally Induced Changes. In Analysis of Burned Human Remains. (pp. 105-117) Florida, United States: CRC Press.

Symes, S., Rainwater, C., Chapman, E., Gipson, D., Piper, A. (2015) Patterned Thermal Destruction in a Forensic Setting. In Analysis of Burned Human Remains. (pp. 17-59) Florida, United States: CRC Press.

Shipman, P., Foster, G., \& Schoeninger, M. (1984). Burnt Bones and Teeth: an Experimental Study of Color, Morphology, Crystal Structure and Shrinkage. Journal of Archaeological Science. 11, 307-325 http://anthropology.ucsd.edu/_files/Faculty\%20Files/schoeninger-publications /Foster

Thompson, T. (2015). The Analysis of Heat-Induced Crystallinity Change in Bone. In Analysis of Burned Human Remains. (pp. 323-337) Florida, United States: CRC Press.

Ubelaker, D. (2008). The Forensic Evaluation of Burned Skeletal Remains: A Synthesis Forensic Science International,1-4.https://repository.si.edu/bitstream/handle/10088/ 8212/Ubelaker_the_forensic_evaluation_of_burned_skeletal_remains.pdf?sequence=1

Waterhouse, K. (2013a). The Effect of Victim Age on Burnt Bone Fragmentation: Implications for Remains Recovery. Forensic Science International. 231, 409.e1-409.e7.

Waterhouse, K. (2013b). Post-Burning Fragmentation of Calcined Bone: Implications for Remains Recovery from Fatal Fire Scenes. Journal and Forensic and Legal Medicine, 20, 1112-1117. 